\title{
Repetibilidade de variáveis produtivas e qualitativas da forragem e da excreta bovina em pastagem de braquiária
}

\author{
Vicente Imbroisi Teixeira(1), José Carlos Batista Dubeux Jr.(1), Alexandre Carneiro Leão de Mello(1), \\ Mário de Andrade Lira Jr. ${ }^{(1)}$, Mario de Andrade Lira ${ }^{(2)}$ e Felipe Martins Saraiva(1)
}

(1)Universidade Federal Rural de Pernambuco, Rua Dom Manoel de Medeiros, s/no, Dois Irmãos, CEP $52171-900$ Recife, PE.
E-mail: vicente_imbroisi@hotmail.com, dubeux@dz.ufrpe.br, mello@dz.ufrpe.br, mario.lira@depa.ufrpe.br, felmart@ig.com.br
(2)Instituto Agronômico de Pernambuco, Avenida General San Martin, no 1371, Bongi, CEP 50761-000 Recife, PE. E-mail: mariolira@terra.com.br

Resumo - O objetivo deste trabalho foi determinar a repetibilidade e o número de avaliações necessárias para se obter coeficiente de determinação superior a $90 \%$ em variáveis produtivas e qualitativas de forragem e de excreta bovina, em pastagem de capim-braquiária (Urochloa decumbens). As variáveis avaliadas foram: produção fecal, composição mineral das fezes e da forragem ao redor, biometria das fezes, massa e rejeição de forragem ao redor das fezes, volume urinário e composição mineral da urina. Utilizou-se lotação intermitente fixa, com três dias de ocupação e 32 ou 67 de descanso, nas épocas chuvosa e seca, respectivamente. As análises de repetibilidade foram obtidas pelo programa Genes, com o método dos componentes principais baseado na matriz de covariância. Os coeficientes de repetibilidade (r) foram elevados, e os $\mathrm{R}^{2}$ iguais ou superiores a $90 \%$, exceto quanto à massa de forragem $(20-40 \mathrm{~cm})$, diferença de altura da forragem com fezes entre o pré e pós-pastejo e teor de $\mathrm{N}$ na urina, no tratamento com 3,2 unidades animais por hectare $(\mathrm{r}<0,50)$. Para obter $\mathrm{R}^{2}>90 \%$, seriam necessárias 11, 9 e 9 avaliações para as variáveis forragem, fezes e urina, respectivamente.

Termos para indexação: Urochloa decumbens, fezes bovinas, fósforo, nitrogênio, potássio, urina bovina.

\section{Repeatability of productive and qualitative variables of forage and cattle excreta on signal grass pasture}

\begin{abstract}
The objective of this work was to determine the repeatability and the number of the required evaluations to obtain determination coefficient greater than $90 \%$ in the productive and qualitative variables of forage and cattle excreta on a signal grass (Urochloa decumbens) pasture. The utilized variables were: fecal production, feces mineral composition, herbage mineral composition around dung pads, feces biometry, herbage mass and herbage rejection around dung pads, urinary volume, and urine chemical composition. A fixed rotational stocking was used, with three days of occupation and 32 or 67 days of resting period, during the rainy and dry seasons, respectively. Repeatability analyzes were obtained with the software Genes, using the principal component method based on the covariance. The repeatability coefficients (r) had high estimates, and the $\mathrm{R}^{2}$ were equal to or greater than $90 \%$, except for herbage mass at $20-40 \mathrm{~cm}$, for the difference between pre- and post-grazing herbage height of herbage grown on dung pad, and for nitrogen concentration in the urine for the treatment with 3,2 animal units per hectare $(r<0.50)$. For $\mathrm{R}^{2}$ above $90 \%$, the number of evaluations required would be 11,9 , and 9 , for the variables forage, feces, and urine, respectively.
\end{abstract}

Index terms: Urochloa decumbens, cattle feces, phosphorus, nitrogen, potassium, cattle urine.

\section{Introdução}

A braquiária, Urochloa decumbens (Stapf.) R.D. Webster (Syn. Brachiaria decumbens), é uma gramínea com diversas características importantes, tais como a de ser perene e apresentar elevada produção de matéria seca e de sementes (Vilela, 2005). Isto faz com que esta espécie seja largamente cultivada como forrageira no Brasil.
Segundo Peron \& Evangelista (2004), a falta de adubação de manutenção nas pastagens, ou seja, a não reposição de nutrientes a este ecossistema é uma das principais causas de sua degradação. Segundo Barcellos et al. (2008), estima-se que a adubação média anual, em pastagens brasileiras, seja de 2,9 a 3,6 kg ha ${ }^{-1}$ de fertilizantes minerais.

Para uma adequada reposição de nutrientes a essas pastagens, são necessários estudos referentes à

Pesq. agropec. bras., Brasília, v.46, n.6, p.655-662, jun. 2011 
ciclagem de nutrientes, alguns dos quais vêm sendo conduzidos em campo, na Zona da Mata de Pernambuco (Silva, 2009a; Saraiva, 2010). Contudo, experimentos realizados em campo, normalmente, apresentam custo e coeficiente de variação elevados. Para otimizar os recursos e manter determinada confiança nos resultados obtidos, pode-se fazer uso de informações geradas pelas análises de repetibilidade. Segundo Cruz et al. (2004), uma das grandes utilidades deste tipo de análise é a determinação do número de observações necessárias para que o valor real da variável analisada seja estimado com a precisão desejada e com o mínimo de custo e mão de obra.

O objetivo deste trabalho foi determinar a repetibilidade e o número de avaliações necessárias para se obter coeficiente de determinação superior a 90\% em variáveis produtivas e qualitativas de forragem e de excreta bovina, em pastagem de capim-braquiária.

\section{Material e Métodos}

OexperimentofoiconduzidonaEstaçãoExperimental do Instituto Agronômico de Pernambuco (IPA), no Município de Itambé, Zona da Mata seca de PE, a $07^{\circ} 25^{\prime} \mathrm{S}, 35^{\circ} 06^{\prime} \mathrm{W}$, à altitude $190 \mathrm{~m}$, com médias anuais de precipitação e temperatura de $1.200 \mathrm{~mm}$ e $25^{\circ} \mathrm{C}$, respectivamente (Companhia Pernambucana do Meio Ambiente, 2003). O período experimental estendeu-se de março de 2008 a outubro de 2009 , em duas estações chuvosas. O clima é classificado como do tipo subúmido megatérmico (Thornthwaite \& Matter, 1995), e o total de chuva acumulada (Figura 1) durante o período experimental foi de $2.315 \mathrm{~mm}$ (Instituto de Tecnologia de Pernambuco, 2010). O solo da estação experimental

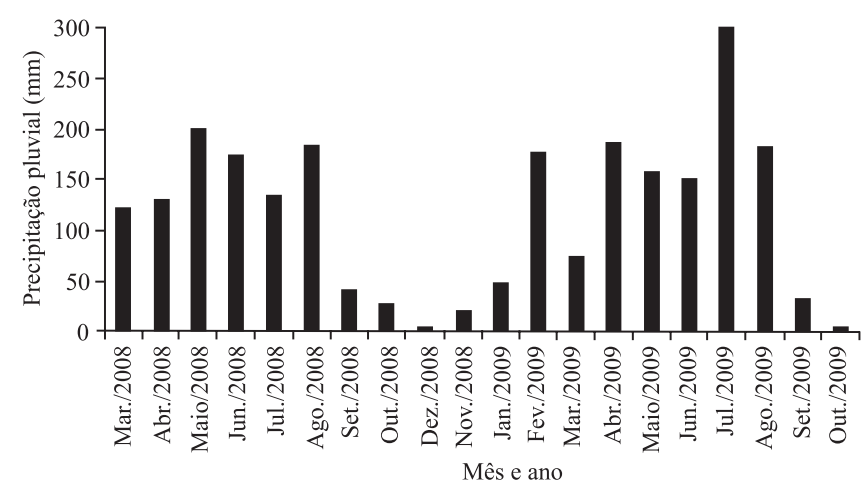

Figura 1. Precipitação pluvial em Itambé, PE, durante o período experimental (março de 2008 a outubro de 2009). Fonte: Instituto de Tecnologia de Pernambuco (2010). é classificado como Argissolo Vermelho-Amarelo, de textura média argilosa (Jacomine et al., 1972). O solo, no início do período experimental, apresentava, à profundidade de 0 a $20 \mathrm{~cm}$, as seguintes características químicas, conforme Claessen (1997): $\mathrm{pH}$ em água, 5,6; $\mathrm{P}$ (Mehlich-1), 12,9 $\mathrm{mg} \mathrm{dm}{ }^{-3} ; \mathrm{Na}^{+}, 0,4 \mathrm{cmol}_{\mathrm{c}} \mathrm{dm}^{-3} ; \mathrm{K}^{+}$, 0,5 $\mathrm{cmol}_{\mathrm{c}} \mathrm{dm}^{-3} ; \mathrm{Mg}^{2+}, 2,1 \mathrm{cmol}_{\mathrm{c}} \mathrm{dm}^{-3} ; \mathrm{Ca}^{2+}, 3,6 \mathrm{cmol}_{\mathrm{c}}$ $\mathrm{dm}^{-3} ; \mathrm{Al}^{3+}, 0,22 \mathrm{cmol}_{\mathrm{c}} \mathrm{dm}^{-3} ; \mathrm{Ca}^{2+}, 0,8 \mathrm{cmol}_{\mathrm{c}} \mathrm{dm}^{-3} ; \mathrm{H}+$ $\mathrm{Al}^{3+}, 4,9 \mathrm{cmol}_{\mathrm{c}} \mathrm{dm}^{-3}$.

Aárea experimental apresentava o seguinte histórico: 1977 a 1980, ensaios experimentais com sorgo; 1981 a 2001, cultivo com $U$. decumbens; 2001 a 2006, ensaios experimentais com clones de capim-elefante; e de 2006 à data de realização do experimento, ensaios com $U$. decumbens.

O experimento foi implantado em pastagens manejadas com lotação intermitente fixa. Nas avaliações de março de 2008 a março de 2009, os animais - vacas lactantes 5/8 Holandesa/Zebu, com peso corporal médio de $526 \pm 52 \mathrm{~kg}$ - permaneceram três dias em cada piquete, com períodos de descanso de 32 e 67 dias, nas épocas chuvosa e seca, respectivamente. Nas avaliações a partir de março de 2009 (quatro no total), o período de ocupação foi de 1 dia, e o de descanso foi de 35 dias. Essa alteração decorreu da diminuição da área dos piquetes $\left(833 \mathrm{~m}^{2}\right)$ nas avaliações realizadas no ano de 2008 até março de 2009. A partir de então (março de 2009), as mesmas áreas foram divididas em três piquetes com $277 \mathrm{~m}^{2}$ cada. As avaliações foram feitas em apenas um dos piquetes de $277 \mathrm{~m}^{2}$.

Os animais, no período chuvoso, eram alimentados exclusivamente em pasto, mas no período seco recebiam suplementação com concentrado e sal mineral no momento da ordenha, além de mistura de cana de açúcar com 1\% de ureia/sulfato de amônio (9:1).

Os tratamentos consistiram de três lotações animais com 2, 4 e 6 unidades animais (UA) por hectare, respectivamente, em que 1 UA corresponde a $450 \mathrm{~kg}$ de peso vivo animal. No entanto, a lotação real média, obtida no decorrer do experimento, foi de 1,9, 3,2 e 4,2 UA ha-1.

Após a saída dos animais, nos ciclos de março, maio, junho, julho e agosto de 2008, as parcelas foram adubadas com doses equivalentes a $300 \mathrm{~kg} \mathrm{ha}^{-1}$ do fertilizante NPK 20-10-20, no total de 60,30 e $60 \mathrm{~kg}$ ha ano ${ }^{-1}$ de $\mathrm{N}, \mathrm{P}_{2} \mathrm{O}_{5}$ e $\mathrm{K}_{2} \mathrm{O}$, respectivamente. Após as avaliações realizadas em março de 2009, as parcelas foram adubadas anualmente com quantidade de ureia 
equivalente a $300 \mathrm{~kg} \mathrm{ha}^{-1}$ de $\mathrm{N}$, dividida em cinco aplicações. No total, as avaliações foram realizadas em 13 ciclos de pastejo (Tabela 1), com intervalo entre duas avaliações sucessivas de 35 e 70 dias, para as épocas chuvosa e seca, respectivamente.

As variáveis avaliadas foram: massa e composição química da forragem, em diferentes distâncias da placa de fezes; rejeição da forragem ao redor das placas de fezes; produção fecal e volume urinário; composição química das fezes e da urina; área e peso das placas de fezes.

Para a determinação da massa de forragem, foram marcadas, após o período de pastejo do ciclo anterior, três placas de fezes por parcela. No pré-pastejo do ciclo subsequente, foram colhidas, agrupadas e pesadas, por zona, todas as plantas cuja base do colmo estivessem à distância de 0 a 20, 20 a 40, e 40 a 60 cm da extremidade da placa de fezes, respectivamente para as zonas 20, 40 e 60. A área de cada zona baseava-se na distância da área média das placas de fezes. O material colhido, nas respectivas zonas, formou amostras compostas em que foram determinados os teores de matéria seca (MS) e a composição química, conforme Silva \& Queiroz (2006).

$\mathrm{Na}$ avaliação da rejeição da forragem, foram marcadas, após o período de pastejo do ciclo anterior, três placas de fezes por parcela (diferentes das utilizadas para determinar a massa da forragem). No pré-pastejo do ciclo subsequente, foi mensurada a altura média do dossel ao redor de cada placa de fezes marcada e, para isto, foi colocada em uma das extremidades da placa, a borda da moldura quadrangular de PVC de $0,25 \mathrm{~m}^{2}$. Quanto à altura do dossel, utilizou-se a média de quatro pontos presentes no interior da moldura, tendose considerado como altura do dossel o comprimento, mensurado com fita métrica, entre o solo e a parte da

Tabela 1. Número de ciclos e período das avaliações durante o experimento.

\begin{tabular}{lcc}
\hline Avaliação & Ciclos & Período \\
\hline Composição mineral da forragem & 13 & Março de 2008 a outubro de 2009 \\
Massa de forragem & 9 & Abril de 2008 a agosto de 2009 \\
Rejeição da forragem & 8 & Julho de 2008 a outubro de 2009 \\
Composição mineral das fezes & 8 & Março de 2008 a março de 2009 \\
Produção fecal & 8 & Março de 2008 a março de 2009 \\
Volume urinário & 8 & Março de 2008 a março de 2009 \\
Biometria das fezes & 7 & Março de 2008 a janeiro de 2009 \\
Composição mineral da urina & 7 & Abril de 2008 a março de 2009 \\
\hline
\end{tabular}

planta (folha ou colmo) localizada ao mesmo nível da borda da moldura.

Em cada placa marcada, foi identificado um ponto $\left(0,25 \mathrm{~m}^{2}\right.$ de área) sem a presença de fezes (amostra pareada). Este ponto apresentava, visualmente, massa de forragem semelhante à observada ao redor das referidas placas de fezes. A altura do dossel deste ponto foi mensurada com o mesmo método descrito anteriormente.

No pós-pastejo, as alturas dos pontos com e sem placas de fezes foram novamente mensuradas. Como rejeição de forragem, considerou-se o resultado obtido pela diferença da altura do dossel nos pontos com fezes, no pré e pós-pastejo, e o resultado obtido pela diferença da altura do dossel nos pontos sem fezes, no pré e pós-pastejo.

A cada ciclo de pastejo foram escolhidos dois animais testadores por parcela - vacas lactantes $5 / 8$ Holandesa/ Zebu, com peso corporal médio de $526 \pm 52 \mathrm{~kg}$. Para esses animais, foi ministrada lignina Lipe purificada e enriquecida P2S2 (Indústria e Comércio Simões Saliba, Belo Horizonte, MG, Brasil) como indicador para a estimativa da produção fecal diária. $\mathrm{O}$ fornecimento de uma cápsula de Lipe de $500 \mathrm{mg}$ por animal foi iniciado um dia antes da entrada dos animais nas parcelas e mantido por 10 dias consecutivos.

No início do segundo e do terceiro dias de pastejo, em cada bloco, quando os animais testadores de cada tratamento eram levados para a ordenha, coletavam-se a urina (10 $\mathrm{mL}$ por vaca) e as fezes (aproximadamente 200 g de matéria fresca por vaca). As amostras de fezes eram acondicionadas em recipientes de alumínio, com tampas de papelão, para serem pesadas e depois levadas à estufa de circulação forçada de ar, a $55^{\circ} \mathrm{C}$ por 72 horas, e novamente pesadas. Para cada parcela, foi formada uma amostra composta, em que as fezes dos dois dias de coleta em cada bloco ( $2^{\circ}$ e $3 \%$ dias de pastejo por bloco) eram reunidas.

Quanto à urina, foram realizadas coletas spot, em que uma alíquota de $10 \mathrm{~mL}$ foi diluída em $40 \mathrm{~mL}$ de ácido sulfúrico a $0,018 \mathrm{~mol} \mathrm{~L}^{-1}$. Após a diluição, o pH foi aferido e, quando necessário, ajustado para valores inferiores a três, com ácido sulfúrico concentrado, para evitar a destruição bacteriana dos derivados de purina. As amostras foram congeladas, para posterior análise de creatinina e minerais.

Para estimar a produção de matéria seca fecal, as fezes foram moídas em moinho tipo Wiley e passadas 
por peneira com malha de $1 \mathrm{~mm}$. Depois de moídas, retiraram-se $10 \mathrm{~g}$ por amostra, que foram enviadas para o Laboratório de Nutrição Animal da Escola de Veterinária da Universidade Federal de Minas Gerais, para a análise em espectrofotômetro de infravermelho Varian 800 (Agilent Technologies, Morges, Suíça), com transformada de Fourrier. O cálculo para estimar a produção fecal (PF) seguiu a equação descrita por Lanzetta et al. (2009). As análises de minerais nas fezes e na urina foram feitas conforme método de Silva \& Queiroz (2006).

A análise de creatinina foi feita no Laboratório de Patologia Veterinária da Universidade Federal Rural de Pernambuco, com uso de kits comerciais Doles (Doles Reagentes e Equipamentos para Laboratórios Ltda., Goiânia, GO, Brasil), com leitura realizada pelo método colorimétrico, segundo Fujihara et al. (1987).

$\mathrm{O}$ volume de urina médio diário foi estimado para cada animal, pela multiplicação do peso vivo (PV) do animal pela excreção diária de creatinina, estimada em 24,4 mg de creatinina por quilograma de peso corporal como padrão (Pereira, 2003), dividido pela concentração de creatinina na urina spot $\left(\mathrm{mg} \mathrm{L}^{-1}\right)$.

No período da manhã do segundo dia de pastejo, foram determinados, em campo, os comprimentos de três placas de fezes por parcela, nos sentidos norte-sul e leste-oeste. Considerou-se como circular o formato de uma placa de fezes e, com a média de seus diâmetros, determinou-se a área média ocupada por elas.

Após a determinação dos comprimentos, as placas de fezes foram coletadas e pesadas, para obtenção da massa de fezes frescas, tendo-se evitado a contaminação com materiais não pertencentes à placa de fezes.
Utilizou-se o delineamento experimental de blocos ao acaso, em arranjo de parcelas subsubdivididas em faixas, com três repetições, com as parcelas principais formadas pelas lotações animais, as subparcelas pelas zonas em torno das placas de fezes, e as subsubparcelas pelo período de avaliação.

A análise de repetibilidade foi realizada com os dados obtidos em 13 ciclos de pastejo, referentes ao período de março de 2008 a outubro de 2009 (Tabela 1), que abrangeu duas estações chuvosas. Para essa análise, usou-se o programa computacional Genes (Cruz, 2006).

Os valores das estimativas dos coeficientes de repetibilidade e de determinação, bem como o número de avaliações necessárias para se obter $\mathrm{R}^{2}$ acima de $90 \%$, foram obtidos pelo método dos componentes principais, com base na matriz de covariância, conforme Cruz et al. (2004). Segundo esses autores, tal método deve ser utilizado em experimentos complexos, em que as variáveis em questão apresentem padrão de comportamento periódico.

Botrel et al. (2000) afirmam que a predição do valor real em torno de $90 \%$ - ou seja, $\mathrm{R}^{2}=90 \%$-, é considerada bastante satisfatória e, por este motivo, foi adotada neste experimento.

\section{Resultados e Discussão}

As estimativas do coeficiente de repetibilidade para a massa de forragem ao redor das placas de fezes variou de 0,48 a 0,94 (Tabela 2). Segundo Cruz et al. (2004), a repetibilidade varia em função da natureza do caráter avaliado, das propriedades genéticas da população e

Tabela 2. Estimativas dos coeficientes de repetibilidade (r) e de determinação $\left(\mathrm{R}^{2}\right)$ e número de avaliações necessárias para que se obtenha $\mathrm{R}^{2}>90 \%$ (NA) para a massa de forragem e para os teores de N, P e K em Urochloa decumbens, nas diferentes distâncias da planta até a placa de fezes ${ }^{(1)}$.

\begin{tabular}{|c|c|c|c|c|c|c|c|c|c|c|c|c|c|}
\hline \multirow{2}{*}{$\begin{array}{l}\text { Lotação } \\
\left(\text { UA ha }^{-1}\right)\end{array}$} & \multirow[t]{2}{*}{ Distância (cm) } & \multicolumn{4}{|c|}{$\mathrm{r}$} & \multicolumn{4}{|c|}{$\mathrm{R}^{2}(\%)$} & \multicolumn{4}{|c|}{ NA } \\
\hline & & Massa & $\mathrm{N}$ & $\mathrm{P}$ & $\mathrm{K}$ & Massa & $\mathrm{N}$ & $\mathrm{P}$ & $\mathrm{K}$ & Massa & $\mathrm{N}$ & $\mathrm{P}$ & $\mathrm{K}$ \\
\hline \multirow{3}{*}{1,9} & $0-20$ & 0,70 & 0,60 & 0,63 & 0,61 & 95,5 & 95,1 & 95,7 & 95,3 & 4 & 6 & 5 & 6 \\
\hline & $20-40$ & 0,65 & 0,84 & 0,78 & 0,71 & 94,3 & 98,6 & 97,8 & 97,0 & 5 & 2 & 3 & 4 \\
\hline & $40-60$ & 0,62 & 0,74 & 0,53 & 0,62 & 93,7 & 97,4 & 93,7 & 95,5 & 6 & 3 & 8 & 6 \\
\hline \multirow{3}{*}{3,2} & $0-20$ & 0,60 & 0,89 & 0,68 & 0,71 & 93,0 & 99,1 & 96,5 & 96,9 & 6 & 1 & 4 & 4 \\
\hline & $20-40$ & 0,48 & 0,65 & 0,68 & 0,80 & 89,4 & 96,0 & 96,5 & 98,1 & 10 & 5 & 4 & 2 \\
\hline & $40-60$ & 0,61 & 0,81 & 0,69 & 0,75 & 93,4 & 98,2 & 96,7 & 97,5 & 6 & 2 & 4 & 3 \\
\hline \multirow{3}{*}{4,2} & $0-20$ & 0,94 & 0,75 & 0,62 & 0,51 & 99,3 & 97,5 & 95,5 & 93,2 & 1 & 3 & 6 & 9 \\
\hline & $20-40$ & 0,73 & 0,76 & 0,75 & 0,65 & 96,0 & 97,6 & 97,5 & 96,0 & 3 & 3 & 3 & 5 \\
\hline & $40-60$ & 0,80 & 0,72 & 0,83 & 0,64 & 97,3 & 97,1 & 98,4 & 95,8 & 2 & 4 & 2 & 5 \\
\hline
\end{tabular}

${ }^{(1)}$ Análise realizada com dados coletados de nove avaliações. 
das condições ambientais sob as quais os indivíduos são mantidos.

Os maiores valores para as estimativas do coeficiente de repetibilidade para a massa de forragem, independentemente da distância da forragem à placa de fezes, foram obtidos no tratamento 4,2 $\mathrm{UA} \mathrm{ha}^{-1}$. Tal resultado pode ser atribuído à menor rejeição da forragem ao redor das placas de fezes observada nesse tratamento. Assim, o consumo deste material no decorrer do ano foi, praticamente, constante.

Nas avaliações realizadas durante a época chuvosa, os animais dos tratamentos 3,2 $\mathrm{UAha}^{-1}$ e principalmente do 1,9 UA ha-1, por apresentarem menor competição por alimento, praticamente não consumiram a forragem ao redor das placas de fezes. Nas avaliações realizadas na época seca, em razão da redução na quantidade da massa de forragem, os animais do 1,9 $\mathrm{UA} \mathrm{ha}^{-1} \mathrm{e}$ principalmente os do $3,2 \mathrm{UA} \mathrm{ha}^{-1}$ foram obrigados a aumentar o consumo da forragem ao redor das placas de fezes. Assim, elevou-se a variação entre as mensurações, o que reduziu a estimativa do coeficiente de repetibilidade para a massa de forragem ao redor das placas de fezes para esses tratamentos (Tabela 2).

Exceto para o tratamento 4,2 UA ha ${ }^{-1}$, na distância 0-20 cm, as estimativas para o coeficiente de repetibilidade para a produção de forragem estiveram dentro da faixa $(0,29$ a 0,79$)$ obtida por Botrel et al. (2000), que estudaram a produção de MS de diferentes cultivares de alfafa, e dentro da faixa $(0,00-0,78)$ obtida por Silva (2006) com Pennisetum sp., porém foram superiores às observadas por Cargnelutti Filho et al. (2004) e Lédo et al. (2008), ambos com experimentos com Panicum maximum $(0,34)$, e por Souza Sobrinho et al. (2010) com Urochloa ruziziensis $(0,43)$.

$\mathrm{O}$ número de ciclos realizados permitiu mais de $90 \%$ de certeza de se ter inferido sobre o valor real do indivíduo, exceto para o tratamento 3,2 $\mathrm{UA} \mathrm{ha}^{-1}$, na distância $20-40 \mathrm{~cm}$.

As estimativas do coeficiente de repetibilidade para os teores de N, P e K, na braquiária ao redor das placas de fezes, variaram de 0,60 a $0,89,0,53$ a 0,83 e 0,51 a 0,80 , respectivamente (Tabela 2 ).

A elevada estimativa do coeficiente de repetibilidade para os teores de $\mathrm{N}, \mathrm{P}$ e $\mathrm{K}$ na forragem resultou, provavelmente, do fato de os ciclos de pastejo terem intervalos fixos. As plantas, portanto, eram coletadas com a mesma idade e, por se tratar do mesmo material genético e da mesma lotação animal e distância, os teores dos minerais na braquiária não variavam muito dentro de cada tratamento. Assim, se a lotação animal variasse com as avaliações para uma mesma parcela, os teores desses minerais apresentariam estimativas do coeficiente de repetibilidade inferiores aos observados.

Shimoya et al. (2002), em estudo realizado com capim-elefante, obtiveram 0,58 e 0,66 como estimativas do coeficiente de repetibilidade para o teor de $\mathrm{N}$ na folha e no colmo, respectivamente. Tais estimativas foram próximas aos menores valores observados no presente experimento (Tabela 2).

Para obter os teores de N, P e K na forragem ao redor das placas de fezes com um coeficiente de determinação acima de $90 \%$, seria necessário um número menor de avaliações do que o utilizado no presente experimento.

A estimativa do coeficiente de repetibilidade, para a diferença da altura entre o pré e o pós-pastejo da forragem com placa de fezes, foi mais elevada nos tratamentos 1,9 e 4,2 UA ha-1, em que os valores de ambas foram semelhantes. Tal fato pode ser explicado por razões opostas, ou seja, em razão da maior competição por alimento, no tratamento $4,2 \mathrm{UA} \mathrm{ha}^{-1}$, os animais consumiram normalmente a forragem ao redor das fezes (pequena rejeição), o que manteve uma diferença de altura da planta mais ou menos constante entre as avaliações. No tratamento 1,9 $\mathrm{UA} \mathrm{ha}^{-1}$, a competição por alimento foi baixa e houve elevada rejeição, portanto, os animais apresentaram baixo consumo da forragem ao redor das fezes e, assim, a diferença de altura permanecia quase que constante entre as avaliações.

A menor estimativa do coeficiente de repetibilidade ocorreu no tratamento 3,2 UA ha-1 ${ }^{-1}$, pois, nas avaliações em que a pastagem apresentou boa disponibilidade de forragem (época chuvosa), o consumo de forragem ao redor das placas de fezes foi baixo, tendo ocorrido o oposto das avaliações de menor oferta de forragem (época seca); consequentemente, este foi o tratamento que apresentou a maior oscilação entre as épocas quanto à diferença de altura da planta entre o pré e o pós-pastejo, o que acarretou menor estimativa do coeficiente de repetibilidade (Tabela 3 ).

O número de avaliações realizadas foi suficiente para que o coeficiente de determinação fosse igual ou superior a $90 \%$, exceto para o tratamento 3,2 UA ha-1, na forragem próxima à placa de fezes. 
A estimativa do coeficiente de repetibilidade das variáveis volume urinário e produção fecal foram menores no tratamento 1,9 UA ha-1 (Tabela 4). A qualidade da forragem e o seu consumo pelo animal podem estar diretamente relacionados a esta resposta. A frequência na ingestão de água pelos bovinos depende da temperatura ambiente, da qualidade do alimento e da distribuição da água (Garçone, 2005). Além disto, este autor afirma que a ingestão de água é maior com o aumento do consumo de matéria seca. Entre tais fatores, os únicos que possivelmente variaram entre os tratamentos foram a qualidade do alimento e o consumo de matéria seca. Os animais do tratamento 1,9 $\mathrm{UA} \mathrm{ha}^{-1}$ foram provavelmente mais influenciados por tais variações. Silva (2009b) observou maior variação no tempo de pastejo, em animais submetidos a esse mesmo tratamento.

O número de avaliações realizadas para determinar a produção fecal e o volume urinário foi suficiente para se obter coeficiente de determinação acima de $90 \%$ (Tabela 4).

Tabela 3. Estimativas dos coeficientes de repetibilidade (r) e de determinação $\left(\mathrm{R}^{2}\right)$, e número de avaliações necessárias para que se obtenha $\mathrm{R}^{2}>90 \%$ (NA), para a variável diferença da altura de Urochloa decumbens entre o pré e o pós-pastejo, com e sem placa de fezes bovinas ${ }^{(1)}$.

\begin{tabular}{lcccc}
\hline Lotação $\left(\mathrm{UA} \mathrm{ha}^{-1}\right)$ & Fezes & $\mathrm{r}$ & $\mathrm{R}^{2}(\%)$ & $\mathrm{NA}$ \\
\hline \multirow{2}{*}{1,9} & Com & 0,84 & 97,7 & 2 \\
& Sem & 0,64 & 93,4 & 5 \\
\multirow{2}{*}{3,2} & Com & 0,45 & 86,9 & 11 \\
& Sem & 0,72 & 95,4 & 4 \\
4,2 & Com & 0,80 & 97,0 & 2 \\
& Sem & 0,53 & 90,0 & 8 \\
\hline
\end{tabular}

(1)Análise realizada com dados coletados de oito avaliações.
A menor estimativa do coeficiente de repetibilidade para o teor de $\mathrm{N}$ nas fezes, observada no tratamento 1,9 UA ha-1 (Tabela 4), pode ser atribuída à maior variação, entre as avaliações, do teor de $\mathrm{N}$ na dieta dos animais. Tal variação pode ser consequência da maior quantidade de forragem velha e da menor quantidade de brotações (não mensurado), resultantes do menor consumo de forragem por área, já que se trata da menor lotação utilizada no experimento.

As estimativas do coeficiente de repetibilidade para o teor de $\mathrm{P}$ presente nas fezes apresentou pequena variação $(0,07)$ entre os tratamentos (Tabela 4$)$, o que indica que a lotação animal não teve influência sobre esta variável.

Para se obterem os teores de N, P e K das fezes com um coeficiente de determinação acima de $90 \%$, é necessário um número de avaliações menor do que o utilizado no presente experimento (Tabela 4). Tal informação irá contribuir para a redução de despesas em futuros experimentos, em que se façam necessárias a análises de N, P e K nas fezes.

As estimativas dos coeficientes de repetibilidade para os teores de $\mathrm{N}$ nas fezes e na urina, no tratamento com 4,2 UA ha-1 ${ }^{-1}$ foram elevados e superiores aos dos demais tratamentos (Tabela 4). Isto pode indicar maior regularidade na ingestão desse elemento pelos animais presentes no tratamento com 4,2 $\mathrm{UA} \mathrm{ha}^{-1}$.

A estimativa do coeficiente de repetibilidade para o teor de $\mathrm{K}$ na urina foi maior no tratamento com 1,9 UA ha-1, o que indica que os animais deste tratamento ingeriram uma dieta com pequena variação no teor desse nutriente entre os ciclos de pastejo, pois, a principal via de excreção deste elemento pelos animais é a urina (Haynes \& Williams, 1993).

Para se obter uma estimativa igual ou superior à $90 \%$ do valor real do teor de $\mathrm{K}$, na urina de vacas em

Tabela 4. Estimativas dos coeficientes de repetibilidade (r) e de determinação $\left(\mathrm{R}^{2}\right)$, e número de avaliações necessárias para que se obtenha $\mathrm{R}^{2}>90 \%$ (NA), para as variáveis produção de excreta fecal $\left(\mathrm{kg} \mathrm{ha}^{-1}\right.$ de MS por dia) e urinária (L ha ${ }^{-1}$ por dia) e teores de N, P e K das fezes e da urina de animais manejados em pastagens de Urochloa decumbens ${ }^{(1)}$.

\begin{tabular}{|c|c|c|c|c|c|c|c|c|c|c|c|c|c|}
\hline \multirow{2}{*}{$\begin{array}{l}\text { Lotação } \\
\left(\text { UA ha }^{-1}\right)\end{array}$} & \multirow[t]{2}{*}{ Excreta } & \multicolumn{4}{|c|}{$\mathrm{r}$} & \multicolumn{4}{|c|}{$\mathrm{R}^{2}(\%)$} & \multicolumn{4}{|c|}{ NA } \\
\hline & & Produção & $\mathrm{N}$ & $\mathrm{P}$ & $\mathrm{K}$ & Produção & $\mathrm{N}$ & $\mathrm{P}$ & $\mathrm{K}$ & Produção & $\mathrm{N}$ & $\mathrm{P}$ & K \\
\hline \multirow[t]{2}{*}{1,9} & Fezes & 0,56 & 0,69 & 0,76 & 0,69 & 91,2 & 94,7 & 96,3 & 94,7 & 7 & 4 & 3 & 4 \\
\hline & Urina & 0,60 & 0,57 & - & 0,85 & 92,3 & 90,2 & - & 97,6 & 6 & 7 & - & 2 \\
\hline \multirow[t]{2}{*}{3,2} & Fezes & 0,77 & 0,72 & 0,83 & 0,88 & 96,5 & 95,4 & 97,5 & 98,3 & 3 & 4 & 2 & 1 \\
\hline & Urina & 0,69 & 0,49 & - & 0,73 & 94,6 & 87,0 & - & 95,1 & 4 & 9 & - & 3 \\
\hline \multirow[t]{2}{*}{4,2} & Fezes & 0,81 & 0,84 & 0,76 & 0,74 & 97,2 & 97,7 & 96,3 & 95,8 & 2 & 2 & 3 & 3 \\
\hline & Urina & 0,81 & 0,87 & - & 0,64 & 97,2 & 98,0 & - & 92,6 & 2 & 1 & - & 5 \\
\hline
\end{tabular}

(1) Análise realizada com dados coletados de sete avaliações. 
lactação, teria sido necessário um número de avaliações menor do que a utilizada no presente experimento. Quanto ao teor de N na urina, apenas no tratamento com 3,2 UA ha ${ }^{-1}$ o número de avaliações não foi suficiente para obter tal estimativa do valor real; porém, o valor do coeficiente de determinação foi próximo ao desejado (Tabela 4). Este fato indica que a concentração de $\mathrm{N}$ na urina apresenta, entre as avaliações, uma variação superior à encontrada para o teor de $\mathrm{K}$, o que pode ser atribuído ao aumento na proporção de $\mathrm{N}$ excretado via urina, com a concentração deste elemento na dieta do animal (Rotz et al., 2005).

A estimativa do coeficiente de repetibilidade para a área da placa de fezes variou de 0,50 a 0,89 (Tabela 5). A estrutura do relvado pode ter influenciado a área das placas de fezes, ou seja, tanto a altura quanto a densidade da planta forrageira, nas parcelas do tratamento com 4,2 $\mathrm{UA} \mathrm{ha}^{-1}$, apresentaram visualmente a menor variação entre os ciclos de pastejo, o que provavelmente contribuiu para a maior estimativa do coeficiente de repetibilidade para a área da placa de fezes nesse tratamento. O coeficiente de repetibilidade para o peso fresco das fezes foi elevado, e sua variação entre os tratamentos foi pequena $(0,06)$, o que indica que a lotação animal (com animais de pesos semelhantes) possui pequena influência sobre a variação do peso fresco da placa de fezes.

Exceto para o tratamento com 1,9 $\mathrm{UA} \mathrm{ha}^{-1}$, o número de avaliações realizadas para determinar a área da placa de fezes foi suficiente para se obter um coeficiente de determinação acima de $90 \%$, porém o valor observado foi próximo ao desejado (Tabela 6). Com relação ao peso fresco das placas de fezes, o coeficiente de determinação manteve-se sempre acima de 90\%, independentemente do tratamento.

Tabela 5. Estimativas dos coeficientes de repetibilidade (r) e de determinação $\left(\mathrm{R}^{2}\right)$, e número de avaliações necessárias, para que se obtenha $\mathrm{R}^{2}>90 \%$ (NA), para as variáveis área média e peso fresco médio das placas de fezes de vacas em lactação, manejadas em pastagens de Urochloa decumbens ${ }^{(1)}$.

\begin{tabular}{lcccccccc}
\hline \multirow{2}{*}{$\begin{array}{l}\text { Lotação } \\
\left(\text { UA ha }^{-1}\right)\end{array}$} & \multicolumn{2}{c}{$\mathrm{r}$} & & \multicolumn{2}{c}{$\mathrm{R}^{2}(\%)$} & & \multicolumn{2}{c}{ NA } \\
\cline { 2 - 3 } \cline { 7 - 8 } & Área & Peso fresco & & Área & Peso fresco & & Área & Peso fresco \\
\hline 1,9 & 0,50 & 0,70 & & 87,5 & 94,3 & & 9 & 4 \\
3,2 & 0,61 & 0,67 & & 91,7 & 93,3 & & 6 & 4 \\
4,2 & 0,89 & 0,73 & & 98,2 & 95,0 & & 1 & 3 \\
\hline
\end{tabular}

(1)Análise realizada com dados coletados de sete avaliações.
Tabela 6. Número de ciclos realizados e número de ciclos necessários para se obter um coeficiente de determinação acima de $90 \%$, para cada variável.

\begin{tabular}{lcc}
\hline Variável & $\begin{array}{c}\text { Ciclos } \\
\text { realizados }\end{array}$ & $\begin{array}{c}\text { Ciclos necessários } \\
\text { para } \mathrm{R}^{2}>90 \%\end{array}$ \\
\hline Massa de forragem ao redor das placas de fezes & 9 & 10 \\
Teor de N da forragem ao redor da placa de fezes & 13 & 6 \\
Teor de P da forragem ao redor da placa de fezes & 13 & 8 \\
Teor de K da forragem ao redor da placa de fezes & 13 & 9 \\
Rejeição da forragem ao redor da placa de fezes & 8 & 11 \\
Produção de excretas & 8 & 7 \\
Teor de N nas fezes & 8 & 4 \\
Teor de P nas fezes & 8 & 3 \\
Teor de K nas fezes & 8 & 4 \\
Teor de N da urina & 7 & 9 \\
Teor de K da urina & 7 & 5 \\
Área da placa de fezes & 7 & 9 \\
Massa da placa de fezes & 7 & 4 \\
\hline
\end{tabular}

\section{Conclusões}

1. O número de observações utilizadas neste trabalho é suficiente para se obterem coeficientes de repetibilidade elevados e coeficientes de determinação iguais ou superiores a $90 \%$ para a maioria das variáveis.

2. Para se obter coeficiente de determinação acima de $90 \%$, são necessárias 11,9 e 9 avaliações para as variáveis produtivas e qualitativas quanto às medições na forragem, fezes e urina, respectivamente.

\section{Agradecimentos}

Ao Conselho Nacional de Desenvolvimento Científico e Tecnológico pela concessão de bolsas de estudo.

\section{Referências}

BARCELLOS, A. de O.; RAMOS, A.K.B.; VILELA, L.; MARTHA JUNIOR, G.B. Sustentabilidade da produção animal baseada em pastagens consorciadas e no emprego de leguminosas exclusivas, na forma de banco de proteína, nos trópicos brasileiros. Revista Brasileira de Zootecnia, v.37, p.51-67, 2008.

BOTREL, M. de A.; FERREIRA, R. de P.; CRUZ, C.D.; PEREIRA, A.V.; VIANA, M.C.M.; ROCHA, R.; MIRANDA, M. Estimativas de coeficientes de repetibilidade para produção de matéria seca em cultivares de alfafa, sob diferentes ambientes. Revista Ceres, v.47, p.651-663, 2000.

CARGNELUTTI FILHO, A.; CASTILHOS, Z.M. de S.; STORCK, L.; SAVIAN, J.F. Análise de repetibilidade de caracteres forrageiros de Panicum maximum, avaliados com e sem restrição solar. Ciência Rural, v.34, p.723-729, 2004. 
CLAESSEN, M.E.C. (Org.). Manual de métodos de análise de solo. 2.ed. rev. atual. Rio de Janeiro: Embrapa-CNPS, 1997. 212p. (Embrapa-CNPS. Documentos, 1).

COMPANHIA PERNAMBUCANA DO MEIO AMBIENTE. Diagnóstico socioambiental do litoral norte de Pernambuco. Recife: CPRH, 2003. 214p.

CRUZ, C.D. Programa Genes: biometria. Viçosa: UFV, 2006. 382 p.

CRUZ, C.D.; REGAZZI, A.J.; CARNEIRO, P.C.S. Modelos biométricos aplicados ao melhoramento genético. 3.ed. Viçosa: UFV, 2004. 480p.

FUJIHARA, T.; ØRSKOV, E.R.; REEDS, P.J. The effect of protein infusion on urinary excretion of purine derivatives in ruminants nourished by intragastric nutrition. The Journal of Agricultural Science, v.109, p.7-12, 1987.

GARÇONE, J.G. Efeito do intervalo entre ordenhas sobre o consumo de matéria seca, comportamento ingestivo e produção de leite de vacas em lactação. 2005. 39p. Dissertação (Mestrado) - Universidade Federal Rural do Rio de Janeiro, Seropédica.

HAYNES, R.J.; WILLIAMS, P.H. Nutrient cycling and soil fertility in the grazed pasture ecosystem. Advances in Agronomy, v.49, p.119-199, 1993.

INSTITUTO DE TECNOLOGIA DE PERNAMBUCO. Instituto de Tecnologia de Pernambuco [home page]. Disponível em: $<$ http://www.itep.br>. Acesso em: 27 jul. 2010.

JACOMINE,P.K.T.; CAVALCANTI,A.C.;BURGOS,N.;PESSOA, S.C.P.J.; SILVEIRA, C.O. da. Levantamento exploratório reconhecimento de solos do Estado de Pernambuco. Recife: DNPEA: SUDENE, 1972. 628p.

LANZETTA, V.A.S.; REZENDE, A.S.C. de; SALIBA, E. de O.S.; LANA, A.M.Q.; RODRIGUEZ, N.M.; MOSS, P.C.B. Validação do Lipe como método para determinar a digestibilidade dos nutrientes em eqüinos. Revista Brasileira de Zootecnia, v.38, p.69-74, 2009.

LÉDO, F.J. da S.; PEREIRA, A.V.; SOBRINHO, F. de S.; AUAD, A.M.; JANK, L.; OLIVEIRA, J.S. e. Estimativas de repetibilidade para caracteres forrageiros em Panicum maximum. Ciência e Agrotecnologia, v.32, p.1299-1303, 2008.

PEREIRA, M.L.A. Proteína na dieta de vacas nos terços inicial e médio de lactação. 2003. 105p. Tese (Doutorado) - Universidade Federal de Viçosa, Viçosa.
PERON, A.J.; EVANGELISTA, A.R. Degradação de pastagens em regiões de cerrado. Revista Ciência e Agrotecnologia, v.28, p.655-661, 2004.

ROTZ, C.A.; TAUBE, F.; RUSSELLE, M.P.; OENEMA, J.; SANDERSON, M.A.; WACHENDORF, M. Whole-farm perspectives of nutrient flows in grassland agriculture. Crop Science, v.45, p.2139-2159, 2005.

SARAIVA, F.M. Ciclagem de nutrientes em pastagens de gramíneas tropicais manejadas sob diferentes intensidades de pastejo. 2010. 73p. Dissertação (Mestrado) - Universidade Federal Rural de Pernambuco, Recife.

SHIMOYA, A.; PEREIRA, A.V.; FERREIRA, R. de P.; CRUZ, C.D.; CARNEIRO, P.C.S. Repetibilidade de características forrageiras do capim-elefante. Scientia Agricola, v.59, p.227-234, 2002.

SILVA, A.M. da. Comportamento ingestivo de vacas e novilhas da raça Girolando em pastagem de Brachiaria decumbens Stapf., sob três taxas de lotação. 2009a. 59p. Dissertação (Mestrado) Universidade Federal Rural de Pernambuco, Recife.

SILVA, D.J.; QUEIROZ, A.C. de. Análise de alimentos: métodos químicos e biológicos. 3.ed. Viçosa: UFV, 2006. 235p.

SILVA, H.M.S. da. Decomposição e composição química de liteira de Brachiaria decumbens Stapf. e Calopogonium mucunoides Desv. 2009b. 68p. Dissertação (Mestrado) - Universidade Federal Rural de Pernambuco, Recife.

SILVA, M. da C. Avaliação de descritores morfológicos e seleção de diferentes tipos de progênies de Pennisetum sp. 2006. 78p. Tese (Doutorado) - Universidade Federal Rural de Pernambuco, Recife.

SOUZA SOBRINHO, F. de; BORGES, V.; LÉDO, F.J. da S.; KOPP, M.M. Repetibilidade de características agronômicas e número de cortes necessários para seleção de Urochloa ruziziensis. Pesquisa Agropecuária Brasileira, v.45, p.579-584, 2010.

THORNTHWAITE, C.W.; MATTER, J.R. The water budget and its use in irrigation. In: THORNTHWAITE, C.W.; MATTER, J.R. (Ed.). Water, the year book of agriculture. Washington: USDA, 1955. p.346-358.

VILELA, H. Pastagem: seleção de plantas forrageiras, implantação e adubação. Viçosa: Aprenda Fácil, 2005. 283p.

Recebido em 21 de fevereiro de 2011 e aprovado em 27 de maio de 2011

Pesq. agropec. bras., Brasília, v.46, n.6, p.655-662, jun. 2011 